\title{
The potential role of infectious agents and pelvic inflammatory disease in ovarian carcinogenesis
}

\author{
Kasper Ingerslev ${ }^{1 *} \mathbb{D}$, Estrid Hogdall ${ }^{2}$, Tine Henrichsen Schnack ${ }^{3}$, Wojciech Skovrider-Ruminski ${ }^{4}$, Claus Hogdall ${ }^{3}$ \\ and Jan Blaakaer ${ }^{1}$
}

\begin{abstract}
Background: The etiological cause of ovarian cancer is poorly understood. It has been theorized that bacterial or viral infection as well as pelvic inflammatory disease could play a role in ovarian carcinogenesis.

Aim: To review the literature on studies examining the association between ovarian cancer and bacterial or viral infection or pelvic inflammatory disease.

Methods: Database search through MEDLINE, applying the medical subject headings: "Ovarian neoplasms", AND "Chlamydia infections", "Neisseria gonorrhoeae", "Mycoplasma genitalium", "Papillomaviridae", or "pelvic inflammatory disease". Corresponding searches were performed in EMBASE, and Web of Science. The literature search identified 935 articles of which 40 were eligible for inclusion in this review.
\end{abstract}

Results: Seven studies examined the association between bacterial infection and ovarian cancer. A single study found a significant association between chlamydial infection and ovarian cancer, while another study identified Mycoplasma genitalium in a large proportion of ovarian cancer cases. The remaining studies found no association. Human papillomavirus detection rates varied from 0 to $67 \%$ and were generally higher in the Asian studies than in studies from Western countries. Cytomegalovirus was the only other virus to be detected and was found in 50\% of cases in a case-control study. The association between ovarian cancer and pelvic inflammatory disease was examined in seven epidemiological studies, two of which, reported a statistically significant association.

Conclusions: Data indicate a potential association between pelvic inflammatory disease and ovarian cancer. An association between ovarian cancer and high-risk human papillomavirus genotypes may exist in Asia, whereas an association in Western countries seems unlikely due to the low reported prevalence. Potential carcinogenic bacteria were found, but results were inconsistent, and further research is warranted.

Keywords: Ovarian cancer, Bacterial infection, Viral infection, Pelvic inflammatory disease, Carcinogenesis

\section{Background}

Ovarian cancer (OC) is a major threat to female health, with a global prevalence of 239,000 cases in 2012 [1]. Due to the lack of symptoms in early stage OC, advanced disease is often present at the time of diagnosis [2].

Almost $90 \%$ of OC originates from epithelial cells, which have been thought to arise from the surface mesothelial lining of the ovaries. However, recent

\footnotetext{
* Correspondence: kasper.hjorth.ingerslev@rsyd.dk

'Department of Gynaecology and Obstetrics, Odense University Hospital,

Denmark, Soendre Blvd. 29, 5000 Odense C, Denmark

Full list of author information is available at the end of the article
}

research has indicated that a proportion of serous epithelial OC could originate in precancerous lesions called "serous tubal intraepithelial carcinomas" (STICs) located in the fimbriated end of the fallopian tubes [3]. This is an important finding because previous theories of ovarian carcinogenesis have been unable to explain the fact that precancerous lesions have never been identified in the ovaries [3].

The female internal genitalia and the peritoneal cavity are accessible to outside pathogens through the genital tract. The mesothelial lining of the peritoneal cavity is 
identical in both sexes. However, primary serous peritoneal cancer, which may represent a continuum with serous OC [3], occurs almost exclusively in female patients [4]. This suggests that extrinsic factors could play a crucial role in ovarian carcinogenesis. Furthermore, epidemiological studies have demonstrated that patients with tubal factor infertility have a higher risk of OC [5]. Since the fallopian tubes are often affected by pelvic inflammatory disease (PID), it is therefore highly relevant to consider the potential role of infectious agents in OC. Previous reviews have focused on human papillomavirus (HPV) and OC, but this review is the first to include studies on all bacterial and viral infections as well as studies on pelvic inflammatory disease (PID).

\section{Material and methods}

To review the existing literature on $\mathrm{OC}$ and infectious agents, we performed a systematic literature search by means of a database search for English language articles published in the period from 1980 to 2016. Using the Pubmed research tool, the keyword: "ovarian neoplasms" was by means of the Boolean logical "AND", combined with the following keywords: "Chlamydia infections"
(MeSH), "Neisseria gonorrhoeae" (MeSH), "Mycoplasma genitalium" (MeSH), "Papillomaviridae" (MeSH), "pelvic inflammatory disease" (MeSH). Correspondent searches were performed in EMBASE and Web of Science. The initial search identified 935 articles. After removal of 130 duplicates, 805 studies remained for further analysis. Contents were outside the scope of the present review in 740 articles that were excluded. The remaining 65 articles were subjected to full-text screening. Original studies, examining the association between infectious agents and ovarian cancer by use of tissuebased or serologic methods were included. Epidemiological studies examining the association between pelvic inflammatory disease and ovarian cancer were also included. Case-reports and reviews were excluded, leaving a total of 40 articles to be included in the review. More detailed information on the search strategy is given in the "Additional file 1" to this article.

\section{Viral agents investigated in relation to ovarian carcinogenesis}

Table 1 summarises the viruses investigated in relation to $\mathrm{OC}$, and their potential oncogenic mechanisms.

Table 1 Carcinogenic mechanisms of investigated viruses in relation to ovarian cancer

\begin{tabular}{|c|c|c|c|c|}
\hline Virus & Viral family & $\begin{array}{l}\text { Key viral transforming } \\
\text { factors }\end{array}$ & Mechanisms & Associated cancers \\
\hline Human papillomavirus & Papillomaviridae & $\begin{array}{l}\text { E6 } \\
\text { E7 }\end{array}$ & $\begin{array}{l}\text { Inhibition of apoptosis } \\
\text { Immune evasion } \\
\text { Cell cycle arrest } \\
\text { Immune evasion }[8,10,11]\end{array}$ & $\begin{array}{l}\text { Anal/rectal cancer } \\
\text { Cervical cancer } \\
\text { Oro-pharyngeal cancer } \\
\text { (Ovarian cancer) }^{\mathrm{a}} \\
\text { Penile cancer } \\
\text { Vaginal } \\
\text { Vulvar cancer }\end{array}$ \\
\hline Epstein bar virus & Herpesviridae & $\begin{array}{l}\text { EBNA } 1 \\
\text { EBNA } 2 \\
\text { EBNA-3A } \\
\text { Latent membrane } \\
\text { protein } 1\end{array}$ & $\begin{array}{l}\text { Inhibition of apoptosis } \\
\text { B-cell growth transformation } \\
\text { Cell cycle disruption } \\
\text { Cell cycle disruption } \\
\text { Inhibition of apoptosis } \\
\text { Promotion of cell immortalisation }[48,49]\end{array}$ & $\begin{array}{l}\text { Burkitt lymphoma } \\
\text { Gastric adenocarcinoma } \\
\text { Hodgkin lymphoma } \\
\text { Nasopharyngeal carcinoma } \\
\text { Non-Hodgkin lymphoma } \\
\text { (Ovarian cancer) } \\
\text { Post-transplant lymphoproliferative } \\
\text { disease }\end{array}$ \\
\hline \multirow[t]{2}{*}{ Cytomegalovirus } & Herpesviridae & IE1/IE2 & $\begin{array}{l}\text { Inhibition of antiviral immune response } \\
\text { Inhibition of apoptosis }\end{array}$ & $\begin{array}{l}\text { Mucoepidermoid carcinoma of } \\
\text { salivary glands } \\
\text { (Ovarian cancer) }\end{array}$ \\
\hline & & US28 gene & Enhanced proliferative signaling [44, 45] & \\
\hline $\begin{array}{l}\text { John Cunningham virus/ } \\
\text { BK virus }\end{array}$ & Polyomaviridae & T-antigen/t-antigen & $\begin{array}{l}\text { Cell cycle disruption Inhibition of } \\
\text { apoptosis [56] }\end{array}$ & (Ovarian cancer) \\
\hline \multirow[t]{2}{*}{ Hepatitis $C$ virus } & Flaviviridae & (Indirect) & $\begin{array}{l}\text { Chronic inflammation and oxidative stress } \\
\text { Inhibition of antioxidant systems }\end{array}$ & $\begin{array}{l}\text { Hepatocellular carcinoma } \\
\text { (Ovarian cancer) }\end{array}$ \\
\hline & & $\begin{array}{l}\text { (Direct) } \\
\text { NS5B } \\
\text { NOS2A } \\
\text { NS3/4A protease }\end{array}$ & $\begin{array}{l}\text { Cell cycle disruption } \\
\text { Inhibition of apoptosis } \\
\text { Inhibition of DDR response [51-53] }\end{array}$ & \\
\hline
\end{tabular}

DDR Double-stranded DNA Repair, EBNA Epstein Barr virus nuclear antigen, IE Immediate early genes, NOS2A Nitric oxide synthase 2A, NS3/4A/5B Nonstructural protein $3 / 4 \mathrm{~A} / 5 \mathrm{~B}$

${ }^{a}$ Causality is controversial and is still under investigation 


\section{Human papillomavirus infection}

$\mathrm{HPV}$ infection is a prerequisite for cervical cancer development and is implicated in a range of other cancer forms such as vulvar, penile, anal, and oropharyngeal cancers. To date, The International Agency for Research on Cancer has classified 12 HPV subtypes as human carcinogens: HPV16/18/31/33/35/39/45/51/52/ 56/58/59 [6]. In HPV-induced tumorigenesis, the viral oncogenes E6 and E7 are integrated into the host cell DNA, allowing viral oncoproteins to be expressed by the cell [7]. The carcinogenic mechanisms of these oncoproteins involve the ability of E6 to form a trimeric complex with P53 and the cellular E3 ubiquitin ligase, E6AP. This complex induces proteasomal degradation of P53, which leads to inhibition of cellregulatory mechanisms and apoptosis and, therefore, permits continuous cell proliferation despite irreparable DNA damage [8]. E7 can cause degradation of retinoblastoma protein, which is an important regulator of the cell cycle [9]. Furthermore, E7 can interact with several cell cycle regulators including cyclins, cyclin-dependent kinases, CDKs-inhibitors, cullin 2, histone deacetylase, AP-1, E2F1, and E2F6 [10]. These actions enable the virus to resume the replicationcompetent state within the infected cells, which is essential for viral DNA synthesis. E6 and E7 can also exhibit immunomodulatory effects by downregulating expression of various inflammatory cytokines and by reducing the production of antiviral interferons [11].

HPV is the most studied infectious agent in relation to $\mathrm{OC}$, and the available studies are summarised below.

Six case-control studies, with 11-50 cases of OC, were identified that examined the relation between HPV and OC [12-17]. The applied methods of analysis were either tissue-based methods or serologic assays and included in-situ hybridisation, immunohistochemistry, enzyme-linked immunosorbent serologic assay (ELISA), southern blot hybridisation technique, and polymerase chain reaction (PCR)-based technologies. Only one study found a statistically significant association between HPV and $\mathrm{OC}$ [12]. This study was the largest and included 50 cases with $\mathrm{OC}$ and a control group with 30 patients with non- malignant ovarian lesions. In-situ hybridisation and immunohistochemistry were used to detect the HPV 16 E6 gene in the tumour specimens. The highest detection rates were obtained by in-situ hybridisation, with a prevalence of $52 \%$ among cases as compared to $6.7 \%$ among controls (OR: 16.7 95\% CI: 3.2-71.4). The remaining smaller studies, found no or non-significant associations [13-17].

Twenty-two case-series and cross-sectional studies reporting on the prevalence of HPV in OC tissue were identified (Table 2). HPV 16 was most frequently found and was reported in eight studies, giving a combined total of 60 cases. Ten studies did not find HPV in any of the samples [18-27]. The remaining studies reported a HPV prevalence ranging between 0.5 and 66.7\% [28-39]. Interestingly, the reported HPV prevalence varied according to the geographical region. Among the 572 cases of $\mathrm{OC}$ in Europe and USA combined, 18 cases (3.1\%) were positive for HPV DNA. Studies from the Middle East and Asia, with 347 combined cases of OC, reported 123 cases to be HPV DNA positive (35.4\%).

Recently, sequencing data from The Cancer Genome Atlas (TCGA) database have been utilised to detect HPV oncogene expression in ovarian tumours. Using such data, Roos et al. concluded that six samples in 405 (1.5\%) were positive for HPV18 oncogene expression [40]. However, Khoury et al. performed a similar analysis on 419 serous cystadenocarcinomas from the TCGA database and did not find signs of HPV infection [41]. Moreover, other studies present data that support potential HPV 18 contamination of the TCGA sequencing database and, consequently, question the validity of positive findings $[42,43]$.

\section{Cytomegalovirus infection}

Cytomegalovirus (CMV) is under increasing focus as a carcinogenic virus. It is speculated that rather than initiating malignant transformation, CMV can enhance the growth and migration of tumour cells through a process called "oncomodulation" [44]. For instance, the formation of metastasis may be aided by the capacity of CMV to adhere to and disrupt the endothelial cell integrity by activating $\beta 1 \alpha 5$ integrin on the surface of tumour cells [45]. However, data also indicate that CMV has inherent antiapoptotic and cell cycle modulatory effects [45]. A single study has examined the relation between $\mathrm{OC}$ and CMV. The study detected CMV infection in 12 (50\%) out of 24 cases with $\mathrm{OC}$ and in three (50\%) out of six cases of borderline ovarian tumours. No signs of CMV infection were found in the control group consisting of normal ovarian tissue [13]. These findings have not been confirmed by others.

\section{Epstein-Barr virus and hepatitis $C$ virus infection}

Epstein-Barr virus (EBV) is present in more than $90 \%$ of the global adult population and causes latent infection in the host. [46] It exhibits tropism for epithelial cells, lymphocytes, and mesenchymal cells and is associated with a range of human cancers, including nasopharyngeal carcinoma (NPC) and lymphomas [47]. Its carcinogenic mechanisms include the actions of latent antigens that display effects similar to those of high-risk HPV oncogenes E6 and E7. An example is EBV nuclear antigen (EBNA)-1 that can induce proteasomal degradation of P53 and corresponding inhibition of apoptosis [48]. Likewise, EBNA-3A and $-3 \mathrm{C}$ play an important role in 
Table 2 Studies reporting on HPV prevalence in ovarian cancer tissue

\begin{tabular}{|c|c|c|c|c|c|}
\hline Author \& publication year & Detection method & $\begin{array}{l}\text { HPV genotypes } \\
\text { found }\end{array}$ & $\begin{array}{l}\text { Number of cases } \\
\text { of EOC }\end{array}$ & $\begin{array}{l}\text { Number of HPV } \\
\text { positive cases }\end{array}$ & HPV prevalence (\%) \\
\hline Ingerslev et al. (2016) [28] & PCR & 18 & 191 & 1 & 0.5 \\
\hline Al-Shabanah et al. (2013) [29] & PCR & $16,18,45$ & 100 & 42 & 42.0 \\
\hline Malisic et al. (2012) [30] & PCR & 16 & 54 & 4 & 7.4 \\
\hline Bilyk et al. (2011) [31] & PCR & 16,18 & 53 & 9 & 16.9 \\
\hline Idahl et al. (2010) [18] & PCR & & 52 & 0 & 0 \\
\hline Giordano et al. (2008) [32] & PCR & Not specified & 50 & 1 & 2.0 \\
\hline Wentzensen et al. (2008) [19] & PCR & & 74 & 0 & 0 \\
\hline Atalay et al. (2007) [33] & PCR & 16,33 & 94 & 8 & 8.5 \\
\hline Quirk et al. (2006) [20] & PCR & & 16 & 0 & 0 \\
\hline Yang et al. (2003) [34] & $P C R$ & 16,18 & 56 & 19 & 33.9 \\
\hline Ip et al. (2002) [35] & PCR & 16,18 & 60 & 6 & 10 \\
\hline Li et al. (2002) [36] & $P C R$ & Not specified & 39 & 26 & 66.6 \\
\hline Antilla et al. (1999) [21] & PCR & & 98 & 0 & 0 \\
\hline Chen et al. (1999) [22] & PCR & & 20 & 0 & 0 \\
\hline Strickler et al. (1998) [37] & ELISA & 16 & 16 & 1 & 6.2 \\
\hline Zimna et al. (1997) [38] & PCR & 18 & 18 & 7 & 38.8 \\
\hline Anwar et al. (1996) [23] & PCR & & 3 & 0 & 0 \\
\hline Runnebaum et al. (1995) [24] & PCR & & 26 & 0 & 0 \\
\hline Trottier et al. (1995) [25] & PCR & & 22 & 0 & 0 \\
\hline Lai et al. (1994) [39] & PCR & 16,18 & 18 & 11 & 61.1 \\
\hline Beckmann et al. (1991) [26] & PCR & & 18 & 0 & 0 \\
\hline de Villiers (1986) [27] & Southern blot hybridisation & & 7 & 0 & 0 \\
\hline
\end{tabular}

cell cycle regulation and EBNA-2 antigen is suspected to cause primary B-cell growth transformation and maintain human B-cell immortalisation [49]. Hepatitis $\mathrm{C}$ virus $(\mathrm{HCV})$ is another investigated microorganism in relation to OC. Chronic HCV infection greatly increases the risk of subsequent hepatocellular carcinoma [50]. The mechanisms are not fully understood but may entail different pathways. The chronic inflammation enhances a pro-carcinogenic microenvironment through the release of nitric oxide (NO) and reactive oxygen species (ROS). This process is further mediated by the ability of HCV to increase the cellular generation of $\mathrm{NO}$ and ROS [51] and by its capacity to weaken the antioxidant defence of the host. [52] A more direct pathway involves the ability of $\mathrm{HCV}$ to impair phosphorylation of the ataxia telangiectasia mutated (ATM) kinase substrate, histone 2A.X, which plays a role in initiating cellular response to doublestranded DNA breaks [53]. Despite the obvious carcinogenic potential of $\mathrm{EBV}$ and $\mathrm{HCV}$, only a single study has investigated their potential role in relation to OC. However, this study did not detect EBV or $\mathrm{HCV}$ in 419 serous cystadenocarcinomas from the TCGA database [41].

\section{Polymyoma virus infection}

Finally, a single study has analysed tissue samples for the presence of the BK virus and John Cunningham virus [18]. The oncogenic potential of polymyoma viruses has largely been attributed to viral proteins $\mathrm{T}$ antigen and $\mathrm{t}$-antigen through their interactions with various cellular proteins, including tumour suppressor proteins p53 and pRb [54, 55]. Furthermore, the capability of John Cunningham virus T- antigen to transform rodent cells has previously been demonstrated [56]. In the included study, however, polymyoma viruses were not detected in any of the ovarian cancer tissue samples, nor in the benign controls.

\section{Bacterial agents investigated in relation to ovarian carcinogenesis}

In relation to $\mathrm{OC}$, previous research has focused on the potential association between Chlamydia trachomatis (C. trachomatis), Mycoplasma genitalium (M. genitalium), and Neisseria gonorrhoeae (N. gonorrhoeae) [13, 18, 57-61]. An overview of the potential carcinogenic mechanisms of these bacteria is provided in Table 3 . 
Table 3 Carcinogenic mechanisms of investigated bacteria in relation to ovarian cancer

\begin{tabular}{lll}
\hline Microorganism & Suspected mechanisms & Potentially associated cancers \\
\hline Chlamydia trachomatis & Inhibition of apoptosis & Cervical squamous cell carcinoma \\
& Production of reactive oxygen species & Ovarian cancer \\
Neisseria Gonorrhoeae & DNA strand breaks. Inhibition of P53. & Bladder cancer \\
& Cell cycle disruption [68] & Prostate cancer \\
Mycoplasma Genitalium & Ovarian cancer \\
& Acquisition of anchorage-independent growth & Ovarian cancer \\
\hline
\end{tabular}

DDR Double-stranded DNA Repair

\section{Chlamydia trachomatis infection}

C. trachomatis is a small, obligate intracellular bacterium that has developed several mechanisms to improve its own survival and replication within the host. It can upregulate the production of reactive oxygen species (ROS) through the Mitochondrial Nod-like Family Member NLRX1 [62]. ROS production is normally a cellular defence mechanism against invading microorganisms. However, C. trachomatis can subvert cellular defences and use ROS to improve its own growth through activation of caspase-1 [62]. The resulting increased levels of ROS can lead to doublestranded DNA breaks in the infected cell. Furthermore, C. trachomatis can impair the DNA damage response (DDR) through inhibition of DDR proteins pATM and 53BP1 [63]. Despite the DNA damage, the chlamydia-infected cells continue to proliferate due to increased MAPK signalling and cyclin $\mathrm{E}$ expression [63]. Finally, C. trachomatis can initiate proteasomal degradation of P53 through interaction with the phosphorylated ubiquitin ligase Murine Double Minute 2, leading to inhibition of apoptosis [64]. Combined, these mechanisms promote bacterial survival, but they can also potentially lead to genomic instability, disruption of the cell cycle, and inhibition of apoptosis, all of which are among the hallmarks of cancer [65]. Therefore, C. trachomatis is a suitable candidate for ovarian carcinogenesis. However, the literature on the subject is scarce, and an association between C. trachomatis and OC has been found in only two studies.

One case-control study was based on fresh ovarian tissues from 39 women undergoing laparotomy [13]. The tissue samples, which included 24 cases of OC, six borderline tumours, and nine normal ovaries, were tested for the presence of $C$. trachomatis DNA by PCR techniques. C. trachomatis DNA was detected in $87.5 \%$ of the malignant tumours and $50 \%$ of the borderline ovarian tumours as compared to none of the benign ovarian tissue samples $(\mathrm{OR}=32$ (95\% CI: 3.33, 307.65).

A study by Ness et al. included 117 women with OC and 171 healthy controls [60]. Serologic testing for IgG antibodies of the extracellular elementary bodies (EB) of C. trachomatis was performed. Patients with EOC were more likely to have high levels of $C$. trachomatis EB than the controls in adjusted analysis. In a subgroup analysis, the probability of having $\mathrm{OC}$ was insignificantly increased in patients with the highest levels of IgG EB antibodies compared to the group with the lowest levels (OR $=1.9$ 95\% CI 0.9 3.9). However, these findings are controversial, since four other serologic studies with a total of 626 cases of OC found no association [57-59,61]. Likewise, a single tissue- based study that included $51 \mathrm{OC}$ cases did not find an association [18].

\section{Neisseria gonorrhoeae \& Mycoplasma genitalium infection}

$N$. gonorrhoeae is a small, gram-negative diplococcus that infects epithelial cells and causes cervicitis/urethritis and PID. It has been associated with prostate and bladder cancer $[66,67]$. One study has reported that $N$. gonorrhoeae can cause DNA strand breaks, affect the cell cycle progression, and can decrease the levels of P53 within infected cells [68].

M. genitalium is under increasing focus for its role in PID. Like $N$. gonorrhoeae, its propensity for malignant transformation of host cells is unclear. However, one study revealed that persistent infection of benign human prostate cells with $M$. genitalium resulted in increased migration/invasion [69]. Furthermore, it induced the acquisition of anchorage-independent growth, which allows cells to detach from the surrounding extracellular matrix and metastasise. Finally, it induced karyotypic entropy and malignant transformation proven by the formation of xenograft tumours in immune-compromised mice [69].

Very few studies have investigated the association between M. genitalium or $N$. gonorrhoeae and OC. Only one study reported an association, M. genitalium DNA being detected in 16 (59.3\%) out of 27 samples by a combined PCR and ELISA technique. [70] However, in two separate studies, Idahl et al. found no 
association between $M$. genitalium or $N$. gonorrhoeae and $\mathrm{OC}[18,57]$.

\section{Pelvic inflammatory disease}

Microorganisms that cannot directly induce cellular transformation may still play a role in OC oncogenesis due to the paradoxical effect of the host inflammatory response. It has long been recognised that the cells involved in innate and adaptive immune responses are recruited to the site of tumorigenesis. Here, they can release a multitude of tumour promoting inflammatory cytokines, chemokines, and ROS that can potentially facilitate tumour cell migration, metastasis, and angiogenesis [65]. Cancer has aptly been described as "a wound that does not heal [71]". Several conditions associated with pelvic inflammation such as perineal talc use and endometriosis have been demonstrated to increase the risk of OC [72]. Likewise, ovulation is speculated to induce focal damage and inflammation on the ovarian surface epithelium, and factors that reduce the number of lifetime ovulatory cycles have been shown to reduce the risk of OC [73]. Consequently, it has been speculated that PID could play a role in ovarian carcinogenesis, and the potential association between PID and OC have been investigated in seven case-control studies (Table 4). The majority of studies relied on patient-reported outcomes and identified cases of PID through interviews or questionnaires. Risch et al. reported a statistically significant association between PID and OC (odds ratio (OR) 1.53; 95\% CI 1.10-2.13) [74]. Moreover, they found a dose-response effect in relation to repeated episodes of PID, implying a higher risk of OC with increasing episodes of PID (OR 1.88 ; $95 \%$ CI 1.13-3.12). A prospective, populationbased study from Taiwan verified the diagnosis of PID by the International Statistical Classification of Diseases and Related Health Problems codes registered in a national database [75]. After 3 years of followup, a higher risk of OC was observed in the case group (hazard ratio (HR) 1.92; 95\% CI 1.27-2.92)). In this study, the association was also stronger when analysis was restricted to cases exposed to more episodes of PID (HR 2.46; 95\% CI 1.48-4.09) [75]. However, a statistically significant association between PID and OC could not be confirmed in any of the remaining studies [72, 74, 76-79].

\section{Discussion}

The reviewed studies were very heterogeneous in terms of study population, study design, and the analysis methods used.

However, based on the reviewed studies, it is fair to conclude that high-risk HPV is unlikely to be associated with $\mathrm{OC}$ in Western countries. Interestingly, a higher prevalence was consistently reported in Asia and the Middle East. This finding is supported by previous reviews focusing on HPV and ovarian cancer [80,81] and a potential association may exist in these regions. The geographic variation could be caused by varying potency of HPV strains. Thus, it has been demonstrated that latent infection of the cervix uteri with the non- European variant of HPV 16 is associated with a 2- to 9-fold higher risk of cancer or high- grade cancer precursors, compared to infection with the European variant [82]. Differing genetic predispositions between ethnical groups may also be a factor because polymorphisms of the TP 53 gene or the promoter of the tumour necrosis factor alpha gene have been associated with increased vulnerability to HPV oncogenes [83, 84]. Lastly, environmental or life-style factors could play a role. For instance, the global incidence of EBV infection among adults is estimated to be over $90 \%$, and there is strong evidence linking EBV infection to the development of NPC [47]. Despite the ubiquity of infection, the incidence of NPC is very low in most regions. However, dramatically elevated rates are observed in certain parts of Asia, and dietary factors, such as the intake of salt-preserved fish, are thought to play a role [85]. This

Table 4 Case-control studies on the association between PID and ovarian cancer

\begin{tabular}{|c|c|c|c|c|c|}
\hline Author \& publication year & Region & Data collection & Number of cases & Number of controls & Odds/Hazard- ratios (HR) \\
\hline Rasmussen et al. (2013) [78] & Denmark & Interview & 554 & 1.564 & 0.83 95\% Cl: $0.65-1.05$ \\
\hline Lin et al. (2011) [75] & Taiwan & Database & 67.936 & 135.872 & $\begin{array}{l}1.9295 \% \mathrm{Cl}: 1.27-2.92(\mathrm{HR}) \\
2.4695 \% \mathrm{Cl}: 1.48-4.09^{\mathrm{C}}(\mathrm{HR})\end{array}$ \\
\hline Merritt et al. (2007) [76] & Australia & Questionnaire & 1.576 & 1.509 & 1.15 95\% Cl: 0.85-1.57 \\
\hline Ness et al. (2000) [72] & USA & Interview & 616 & 1.367 & 1.3 95\% Cl: 0.6-2.5 \\
\hline Parazzini et al. (1996) [79] & Italy & Questionnaire/interview & 971 & 2.758 & 0.7 95\% Cl: 0.4-1.3 \\
\hline Risch et al. (1995) [74] & Canada & Interview & 450 & 564 & $\begin{array}{l}1.5395 \% \text { Cl: } 1.10-2.13^{\mathrm{a}} \\
1.8895 \% \text { Cl: } 1.13-3.12^{\mathrm{b}}\end{array}$ \\
\hline Shu et al. (1989) [77] & Hong Kong & Interview & 172 & 172 & 3.0 95\% Cl: $0.3-30.2$ \\
\hline
\end{tabular}

${ }^{\mathrm{a}}$ One episode of PID

${ }^{\mathrm{b}}$ Two or more episodes of PID

cFive or more episodes of PID 
underlines that, even though infection with oncogenic viruses is common, cancer is a rare event that can arise from a combination of genetic, environmental, and lifestyle factors.

Most of the epidemiological studies found an association between OC and PID, but only two studies reported a statistically significant association $[74,75]$. It is noteworthy, however, that these studies also identified a dose- response effect. This is one of the key points in Hill's criteria for causation that state that a biological gradient must be present, with more exposure to the suspected agent leading to a larger effect [86]. These findings are supported by studies that found evaluated markers of inflammation such as CRP and interleukins to be significantly associated with an increased risk of OC [87]. A possible limitation to the reviewed studies is that they relied primarily on patient-reported outcomes, which may be subject to recall bias. Furthermore, due to the potential subclinical course of PID, patients can be unaware of previous episodes. This is supported by studies that have demonstrated a relatively high seroprevalence of chlamydia antibody titres in women that reported no history of PID, and this issue would tend to produce bias towards the null $[88,89]$.

Interestingly, CMV was reported in 50\% of cases in a single study, but this finding requires confirmation in future and larger studies. No other viral agent was detected.

The only detected bacteria were C. trachomatis and $M$. genitalium. The results of this review do not support an association between $C$. trachomatis and $\mathrm{OC}$, the majority of studies reporting negative results. The association between M. genitalium and OC was investigated and found in only a single study and more research is needed.

Several factors may account for the conflicting results. First of all, there may be no connection between the investigated infectious agents and OC. Secondly, the heterogeneity of analysis methods, study populations, and study designs may play a part. However, other explanations must be discussed. Importantly, it is unclear to what extent signs of microbiological agents are present in a tumour that arises decades after infection. For some oncogenic viruses, like high-risk HPV, expression of viral oncogenes is obligate for the maintenance of the malignant phenotype [90]. In these cases, viral genes will remain integrated and detectable in tumour cell DNA. But another potential mechanism is debated in the "hit and run" hypothesis. Here, integration of viral transforming genes and potential epigenetic reprogramming of host cells initiate tumorigenesis, but the viral gene expression is subsequently lost during neoplastic development [91]. Accordingly, it has been demonstrated that CMV oncogenes IE1 and IE2 can cooperate with adenovirus E1A gene to transform rat kidney cells. However, expression of the transforming oncogenes was absent in the clonal cell lines from the transformed foci [92].
Finally, other oncogenic agents act more indirectly by inducing chronic inflammation that may function as an initiator or promoter of carcinogenesis [93]. Consequently, the involved pathogen may no longer be present when cancer is diagnosed. For instance, despite the established role of HCV in hepatocellular carcinoma, only a minority of transformed hepatocytes contain viral RNA [94].

These examples highlight the fact that the abscense of microbiological agents in tumour tissue does not rule out their potential role in the transformation of host cells. These issues seem to strengthen the need for serologic studies. However, serologic methods are limited by the fact that antibody levels are likely to decline over time. In a study from Finland, $43 \%$ of women had declining $C$. trachomatis antibody titres 6 years after the diagnosis of PID [95]. Moreover, not all patients with prior chlamydial infection will have detectable antibodies [96].

These obstacles call for a revised strategy in the attempt to uncover the potential role of infectious agents in OC. It is fair to assume that signs of microbiological presence will be easier to detect when the interval between primary infection and investigation is short. Therefore, it seems more relevant to investigate precursor lesions for the presence of potential microbiological agents [91]. Until recently, this has been impossible due to the lack of a clearly defined premalignant lesion to OC. However, this has changed because increasing evidence indicates that STIC lesions in the distal fallopian tubes are precursor lesions to serous epithelial OC, which constitutes the majority of $\mathrm{OC}$ cases [3]. Yet, no explanation has been formulated as to why STIC lesions arise. Since the fallopian tubes are often affected and damaged by chronic PID, it is biological plausible that pathogens with transforming capacities, or the chronic inflammation they induce, could lead to subsequent neoplastic transformation. We therefore recommend that future studies focus on the detection of bacterial or viral agents in fallopian tube tissue samples with STIC lesions verified through the "Sectioning and Extensively Examining of the Fimbriated end" protocol.

\section{Conclusion}

The reviewed articles indicate a potential association between PID and OC. An association between OC and high-risk HPV genotypes may exist in Asia, whereas an association in Western countries seems unlikely due to the low reported prevalence. Two studies reported an association between bacterial agents and $\mathrm{OC}$, but the majority of bacterial studies reported negative findings. However, the available literature was scarce and more studies are warranted. 


\section{Additional file}

Additional file 1: Systematic literature search. (DOCX $37 \mathrm{~kb}$ )

\section{Abbreviations}

ATM: Ataxia telangiectasia mutated; C. trachomatis: Chlamydia trachomatis; Cl: Confidence interval; CMV: Cytomegalovirus; DDR: Double-stranded DNA Repair.; EBNA: Epstein bar virus nuclear antigen; EBV: Epstein bar virus; ELISA: Enzyme-linked immunosorbent serologic assay; HCV: Hepatitis C virus; HPV: Human papillomavirus; HR: Hazard ratio; IE: Immediate early genes; M. genitalium: Mycoplasma genitalium; N. Gonorrhoeae: Neisseria gonorrhoeae; NO: Nitric oxide; NOS2A: Nitric oxide synthase 2A; NPC: Nasopharyngeal carcinoma; NS3/4A: Nonstructural protein 3/4A; OC: Ovarian cancer; PCR: Polymerase chain reaction; PID: Pelvic inflammatory disease; ROS: Reactive oxygen species; STIC: Serous tubal intraepithelial carcinoma; TCGA: Cancer Genome Atlas database

\section{Acknowledgements}

Not applicable.

\section{Funding}

The study was funded by several grant givers to the "Danish Mermaid III Project". Please see list of individual grant givers at: http://www.mermaidprojektet.dk/en/ about-the-mermaid-project/how-are-we-funded/. The grant givers had no influence on the study design, interpretation of data or in the writing or revision of the manuscript.

\section{Availability of data and materials}

Detailed information on the search strategy and inclusion and exclusion criteria is given the supplementary files.

\section{Authors' contributions}

$\mathrm{Kl}$ : devised the search strategy and performed the literature search and contributed to the development of the proposal, writing of the draft manuscript, and review of the manuscript. EH: contributed to the development of the proposal and participated in review of the manuscript. WS: contributed to the development of the proposal and review of the manuscript. THS: contributed to the development of the proposal and review of the manuscript. $\mathrm{CH}$ : contributed to the development of the proposal and review of the manuscript. JB: Contributed to the conception of the study and to the review and selection of studies as well as to the review of the manuscript. All authors have read and approved the final manuscript.

\section{Competing interests}

The authors declare that they have no competing interests.

\section{Consent for publication}

Not applicable.

\section{Ethics approval and consent to participate} Not applicable.

\section{Publisher's Note}

Springer Nature remains neutral with regard to jurisdictional claims in published maps and institutional affiliations.

\section{Author details}

'Department of Gynaecology and Obstetrics, Odense University Hospital, Denmark, Soendre Blvd. 29, 5000 Odense C, Denmark. ²Department of Pathology, Herlev and Gentofte Hospital, Denmark, Herlev Ringvej 75, 2730 Herlev, Denmark. ${ }^{3}$ Gynaecologic Clinic, Copenhagen University Hospital, Denmark, Blegdamsvej 9, 2100 Copenhagen, Denmark. ${ }^{4}$ Department of Pathology, Herlev Hospital, Denmark, Herlev Ringvej 75, 2730 Herlev, Denmark.
Received: 26 January 2017 Accepted: 26 April 2017

Published online: 18 May 2017

\section{References}

1. Ferlay J, Soerjomataram I, Dikshit R, et al. Cancer incidence and mortality worldwide: sources, methods and major patterns in GLOBOCAN 2012. Int J Cancer. 2015:136:E359-86.

2. Maringe $C$, Walters $S$, Butler J, et al. Stage at diagnosis and ovarian cancer survival: evidence from the International Cancer Benchmarking Partnership. Gynecol Oncol. 2012;127:75-82.

3. Kurman RJ, Shih I. The origin and pathogenesis of epithelial ovarian cancer: a proposed unifying theory. Am J Surg Pathol. 2010;34:433-43.

4. Jermann $M$, Vogt $P$, Pestalozzi BC. "Peritoneal carcinoma in a male patient." Oncology 64.4. 2003;468-72.

5. Brinton LA, Lamb EJ, Moghissi KS, et al. Ovarian cancer risk associated with varying causes of infertility. Fertil Steril. 2004;82:405-14.

6. IARC Working Group on the Evaluation of Carcinogenic Risks to Humans. IARC monographs on the evaluation of carcinogenic risks to humans. Ingested nitrate and nitrite, and cyanobacterial peptide toxins. IARC Monogr Eval Carcinog Risks Hum. 2010;94:1-412. v,vii.

7. Chen $Y$, Williams V, Filippova $M$, et al. Viral carcinogenesis: factors inducing DNA damage and virus integration. Cancers. 2014;6:2155-86.

8. Bernard X, Robinson P, Nomine $Y$, et al. Proteasomal degradation of $\mathrm{p} 53$ by human papillomavirus E6 oncoprotein relies on the structural integrity of p53 core domain. PLoS One. 2011;6:e25981.

9. McLaughlin-Drubin ME, Münger K. The human papillomavirus E7 oncoprotein. Virology. 2009;384:335-44.

10. Boccardo $E$, Lepique AP, Villa LL. The role of inflammation in HPV carcinogenesis. Carcinogenesis. 2010;31:1905-12.

11. Richards KH, Doble R, Wasson CW, et al. Human papillomavirus E7 oncoprotein increases production of the anti-inflammatory interleukin-18 binding protein in keratinocytes. J Virol. 2014;88:4173-9.

12. Wu QJ, Guo M, Lu ZM, et al. Detection of human papillomavirus-16 in ovarian malignancy. Br J Cancer. 2003;89:672-5.

13. Shanmughapriya $S$, Senthilkumar G, Vinodhini $K$, et al. Viral and bacterial aetiologies of epithelial ovarian cancer. Eur J Clin Microbiol Infect Dis. 2012;31:2311-7.

14. Kuscu E, Ozdemir BH, Erkanli S, et al. HPV and p53 expression in epithelial ovarian carcinoma. Eur J Gynaecol Oncol. 2005:26:642-5.

15. Lai CH, Hsueh S, Lin CY, et al. Human papillomavirus in benign and malignant ovarian and endometrial tissues. Int J Gynecol Pathol. 1992;11:210-5

16. Leake JF, Woodruff JD, Searle C, et al. Human papillomavirus and epithelial ovarian neoplasia. Gynecol Oncol. 1989;34:268-73.

17. Hisada M, van den Berg BJ, Strickler HD, et al. Prospective study of antibody to human papilloma virus type 16 and risk of cervical, endometrial, and ovarian cancers (United States). Cancer Causes Control. 2001;12:335-41.

18. Idahl A, Lundin E, Elgh F, et al. Chlamydia trachomatis, Mycoplasma genitalium, Neisseria gonorrhoeae, human papillomavirus, and polyomavirus are not detectable in human tissue with epithelial ovarian cancer, borderline tumor, or benign conditions. Am J Obstet Gynecol. 2010;202:71.e1,71.e6.

19. Wentzensen N, du Bois A, Kommoss S, et al. No metastatic cervical adenocarcinomas in a series of p16INK4a-positive mucinous or endometrioid advanced ovarian carcinomas: an analysis of the AGO Ovarian Cancer Study Group. Int J Gynecol Pathol. 2008;27:18-23.

20. Quirk JT, Kupinski JM, DiCioccio RA. Analysis of ovarian tumors for the presence of human papillomavirus DNA. J Obstet Gynaecol Res. 2006:32:202-5.

21. Anttila M, Syrjanen $\mathrm{S}$, Ji H, et al. Failure to demonstrate human papillomavirus DNA in epithelial ovarian cancer by general primer PCR. Gynecol Oncol. 1999;72:337-41.

22. Chen TR, Chan PJ, Seraj IM, et al. Absence of human papillomavirus E6-E7 transforming genes from HPV 16 and 18 in malignant ovarian carcinoma. Gynecol Oncol. 1999;72:180-2.

23. Anwar $\mathrm{K}$, Nakakuki $\mathrm{K}$, Imai $\mathrm{H}$, et al. Infection of human papillomavirus (HPV) and p53 over-expression in human female genital tract carcinoma. J Pak Med Assoc. 1996:46:220-4.

24. Runnebaum IB, Maier S, Tong XW, et al. Human papillomavirus integration is not associated with advanced epithelial ovarian cancer in German patients. Cancer Epidemiol Biomarkers Prev. 1995;4:573-5. 
25. Trottier AM, Provencher D, Mes-Masson AM, et al. Absence of human papillomavirus sequences in ovarian pathologies. J Clin Microbiol. 1995;33:1011-3.

26. Beckmann AM, Sherman KJ, Saran L, et al. Genital-type human papillomavirus infection is not associated with surface epithelial ovarian carcinoma. Gynecol Oncol. 1991:43:247-51.

27. de Villiers E, Schneider A, Gross G, et al. Analysis of benign and malignant urogenital tumors for human papillomavirus infection by labelling cellular DNA. Med Microbiol Immunol (Berl). 1986;174:281-6.

28. Ingerslev K, Hogdall E, Skovrider-Ruminski W, et al. High-risk HPV is not associated with epithelial ovarian cancer in a Caucasian population. Infect Agent Cancer. 2016;11:1.

29. Al-Shabanah OA, Hafez MM, Hassan ZK, et al. Human papillomavirus genotyping and integration in ovarian cancer Saudi patients. Virol J. 2013;10:343. 422X-10-343.

30. Malisic E, Jankovic R, Jakovljevic K. Detection and genotyping of human papillomaviruses and their role in the development of ovarian carcinomas. Arch Gynecol Obstet. 2012;286:723-8.

31. Bilyk OO, Pande NT, Buchynska LG. Analysis of p53, p16(INK4a), pRb and Cyclin D1 expression and human papillomavirus in primary ovarian serous carcinomas. Exp Oncol. 2011;33:150-6.

32. Giordano G, D'Adda T, Gnetti L, et al. Role of human papillomavirus in the development of epithelial ovarian neoplasms in Italian women. J Obstet Gynaecol Res. 2008;34:210-7.

33. Atalay F, Taskiran C, Taner MZ, et al. Detection of human papillomavirus DNA and genotyping in patients with epithelial ovarian carcinoma. J Obstet Gynaecol Res. 2007;33:823-8.

34. Yang HJ, Liu W, Tsang PC, et al. Comparison of human papillomavirus DNA levels in gynecological cancers: implication for cancer development. Tumour Biol. 2003;24:310-6.

35. Ip SM, Wong LC, Xu CM, et al. Detection of human papillomavirus DNA in malignant lesions from Chinese women with carcinomas of the upper genital tract. Gynecol Oncol. 2002;87:104-11.

36. Li T, Lu Z-M, Guo M, et al. p53 Codon 72 polymorphism (C/G) and the risk of human papillomavirus-associated carcinomas in China. Cancer. 2002;95:2571-6.

37. Strickler HD, Schiffman $\mathrm{MH}$, Shah $\mathrm{KV}$, et al. A survey of human papillomavirus 16 antibodies in patients with epithelial cancers. Eur J Cancer Prev. 1998;7:305-13.

38. Zimna K, Poreba E, Kedzia W, et al. Human papillomavirus (HPV) in upper genital tract carcinomas of women. Eur J Gynaecol Oncol. 1997;18:415-7.

39. Lai $\mathrm{CH}$, Wang $\mathrm{CY}$, Lin $\mathrm{CY}$, et al. Detection of human papillomavirus RNA in ovarian and endometrial carcinomas by reverse transcription/polymerase chain reaction. Gynecol Obstet Invest. 1994;38:276-80.

40. Roos P, Orlando PA, Fagerstrom RM, et al. In North America, some ovarian cancers express the oncogenes of preventable human papillomavirus HPV-18. Sci Rep. 2015;5:8645.

41. Khoury JD, Tannir NM, Williams MD, et al. Landscape of DNA virus associations across human malignant cancers: Analysis of 3,775 cases using RNA-seq. J Virol. 2013;87:8916-26.

42. Kazemian M, Ren M, Lin JX, et al. Possible human papillomavirus 38 contamination of endometrial cancer rna sequencing samples in the cancer genome atlas database. J Virol. 2015;89:8967-73.

43. Cantalupo PG, Katz JP, Pipas JM. HeLa nucleic acid contamination in the cancer genome atlas leads to the misidentification of human papillomavirus 18. J Virol. 2015;89:4051-7.

44. Cinatl J, Scholz M, Kotchetkov R, et al. Molecular mechanisms of the modulatory effects of HCMV infection in tumor cell biology. Trends Mol Med. 2004;10:19-23.

45. Michaelis M, Doerr HW, Cinatl J. The story of human cytomegalovirus and cancer: increasing evidence and open questions. Neoplasia. 2009;11:1-9.

46. de-The G, Day NE, Geser A, et al. Sero-epidemiology of the Epstein-Barr virus: preliminary analysis of an international study - a review. IARC Sci Publ. 1975;11 Pt 2:3-16.

47. Coghill AE, Hildesheim A. Epstein-Barr virus antibodies and the risk of associated malignancies: review of the literature. Am J Epidemiol. 2014;180:687-95.

48. Grywalska E, Rolinski J. Epstein-barr virus-associated lymphomas. Semin Oncol. 2015:42:291-303.

49. Jha HC, Banerjee S, Robertson ES. The role of gammaherpesviruses in cancer pathogenesis. Pathogens. 2016;5:18.

50. Donato F, Tagger A, Gelatti U, et al. Alcohol and hepatocellular carcinoma: the effect of lifetime intake and hepatitis virus infections in men and women. Am J Epidemiol. 2002;155:323-31.
51. Mitchell JK, Lemon SM, McGivern DR. How do persistent infections with hepatitis C virus cause liver cancer? Curr Opin Virol. 2015;14:101-8.

52. Choi J, Corder NL, Koduru B, et al. Oxidative stress and hepatic Nox proteins in chronic hepatitis $C$ and hepatocellular carcinoma. Free Radic Biol Med. 2014;72:267-84.

53. Duong FH, Christen V, Lin S, et al. Hepatitis C virus-induced up-regulation of protein phosphatase $2 \mathrm{~A}$ inhibits histone modification and DNA damage repair. Hepatology. 2010;51:741-51.

54. Khalili K, Del Valle L, Otte J, et al. Human neurotropic polyomavirus, JCV, and its role in carcinogenesis. Oncogene. 2003;22:5181-91.

55. Caracciolo V, Reiss K, Khalili K, et al. Role of the interaction between large $T$ antigen and $\mathrm{Rb}$ family members in the oncogenicity of JC virus. Oncogene. 2006;25:5294-301.

56. Barbanti-Brodano G, Sabbioni S, Martini F, et al. BK virus, JC virus and Simian Virus 40 infection in humans, and association with human tumors. Polyomaviruses and human diseases. New York: Springer; 2006:319-41.

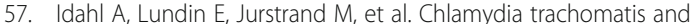
Mycoplasma genitalium plasma antibodies in relation to epithelial ovarian tumors. Infect Dis Obstet Gynecol. 2011;2011:824627.

58. Ness RB, Shen C, Bass D, et al. Chlamydia trachomatis serology in women with and without ovarian cancer. Infect Dis Obstet Gynecol. 2008;2008:219672

59. Wong A, Maclean AB, Furrows SJ, et al. Could epithelial ovarian cancer be associated with chlamydial infection? Eur J Gynaecol Oncol. 2007;28:117-20.

60. Ness RB, Goodman MT, Shen C, et al. Serologic evidence of past infection with Chlamydia trachomatis, in relation to ovarian cancer. J Infect Dis. 2003;187:1147-52.

61. Martin DC, Khare VK, Miller BE, et al. Association of positive Chlamydia trachomatis and Chlamydia pneumoniae immunoglobulin-gamma titers with increasing age. J Am Assoc Gynecol Laparosc. 1997:4:583-6.

62. Abdul-Sater AA, Said-Sadier N, Lam VM, et al. Enhancement of reactive oxygen species production and chlamydial infection by the mitochondrial Nod-like family member NLRX1. J Biol Chem. 2010;285:41637-45.

63. Chumduri C, Gurumurthy RK, Zadora PK, et al. Chlamydia infection promotes host DNA damage and proliferation but impairs the DNA damage response. Cell Host Microbe. 2013;13:746-58.

64. Gonzalez E, Rother M, Kerr MC, et al. Chlamydia infection depends on a functional MDM2-p53 axis. Nat Commun. 2014;5:5201.

65. Hanahan D, Weinberg RA. Hallmarks of cancer: the next generation. Cell. 2011;144:646-74.

66. Michaud D, Platz E, Giovannucci E. Gonorrhoea and male bladder cancer in a prospective study. Br J Cancer. 2007;96:169-71.

67. Lian WQ, Luo F, Song XL, et al. Gonorrhea and prostate cancer incidence: an updated meta-analysis of 21 epidemiologic studies. Med Sci Monit. 2015:21:1902-10.

68. Vielfort $\mathrm{K}$, Soderholm N, Weyler $\mathrm{L}$, et al. Neisseria gonorrhoeae infection causes DNA damage and affects the expression of p21, p27 and p53 in non-tumor epithelial cells. J Cell Sci. 2013;126:339-47.

69. Namiki K, Goodison S, Porvasnik S, et al. Persistent exposure to Mycoplasma induces malignant transformation of human prostate cells. PLoS One. 2009;4:e6872.

70. Chan P, Seraj I, Kalugdan T, et al. Prevalence of Mycoplasma conserved DNA in malignant ovarian cancer detected using sensitive PCR-ELISA. Gynecol Oncol. 1996;63:258-60.

71. Dvorak HF. Tumors: wounds that do not heal. N Engl J Med. 1986;315:1650-9.

72. Ness RB, Grisso JA, Cottreau C, et al. Factors related to inflammation of the ovarian epithelium and risk of ovarian cancer. Epidemiology. 2000;11:111-7.

73. Li J, Fadare $O$, Xiang $L$, et al. Ovarian serous carcinoma: recent concepts on its origin and carcinogenesis. J Hematol Oncol. 2012;5:1.

74. Risch HA, Howe GR. Pelvic inflammatory disease and the risk of epithelial ovarian cancer. Cancer Epidemiol Biomarkers Prev. 1995;4:447-51.

75. Lin HW, Tu YY, Lin SY, et al. Risk of ovarian cancer in women with pelvic inflammatory disease: a population-based study. Lancet Oncol. 201 1;12:900-4.

76. Merritt MA, Green AC, Nagle CM, et al. Talcum powder, chronic pelvic inflammation and NSAIDs in relation to risk of epithelial ovarian cancer. Int J Cancer. 2008;122:170-6.

77. Shu XO, Brinton LA, Gao YT, et al. Population-based case-control study of ovarian cancer in Shanghai. Cancer Res. 1989;49:3670-4.

78. Rasmussen CB, Faber MT, Jensen A, et al. Pelvic inflammatory disease and risk of invasive ovarian cancer and ovarian borderline tumors. Cancer Causes Control. 2013;24:1459-64. 
79. Parazzini F, La Vecchia C, Negri E, et al. Pelvic inflammatory disease and risk of ovarian cancer. Cancer Epidemiol Biomarkers Prev. 1996;5:667-9.

80. Svahn MF, Faber MT, Christensen J, et al. Prevalence of human papillomavirus in epithelial ovarian cancer tissue. A meta-analysis of observational studies. Acta Obstet Gynecol Scand. 2014;93:6-19.

81. Rosa MI, Silva GD, de Azedo Simoes PW, et al. The prevalence of human papillomavirus in ovarian cancer: a systematic review. Int J Gynecol Cancer. 2013;23:437-41.

82. Hildesheim A, Wang SS. Host and viral genetics and risk of cervical cancer: a review. Virus Res. 2002;89:229-40.

83. Zhou X, Gu Y, Zhang S. Association between p53 codon 72 polymorphism and cervical cancer risk among Asians: a HuGE review and meta-analysis. Asian Pac J Cancer Prev. 2012;13:4909-14.

84. Liu L, Yang $X$, Chen $X$, et al. Association between TNF-a polymorphisms and cervical cancer risk: a meta-analysis. Mol Biol Rep. 2012;39:2683-8.

85. Chang ET, Adami HO. The enigmatic epidemiology of nasopharyngeal carcinoma. Cancer Epidemiol Biomarkers Prev. 2006:15:1765-77.

86. HILL AB. The environment and disease: association or causation? Proc R Soc Med. 1965;58:295-300

87. Charbonneau B, Goode EL, Kalli KR, et al. The immune system in the pathogenesis of ovarian cancer. Crit Rev Immunol. 2013;33:137-64.

88. Bjercke S, Purvis K. Characteristics of women under fertility investigation with IgA/lgG seropositivity for Chlamydia trachomatis. Eur J Obstet Gynecol Reprod Biol. 1993;51:157-61.

89. Stamm WE, Holmes KK. Chlamydia trachomatis infections of the adult. Sex Transm Dis. 1999;3:407-22.

90. DeFilippis RA, Goodwin EC, Wu L, et al. Endogenous human papillomavirus E6 and E7 proteins differentially regulate proliferation, senescence, and apoptosis in HeLa cervical carcinoma cells. J Virol. 2003;77:1551-63.

91. Niller HH, Wolf H, Minarovits J. Viral hit and run-oncogenesis: genetic and epigenetic scenarios. Cancer Lett. 2011;305:200-17.

92. Shen $Y$, Zhu H, Shenk T. Human cytomagalovirus IE1 and IE2 proteins are mutagenic and mediate "hit-and-run" oncogenic transformation in cooperation with the adenovirus E1A proteins. Proc Natl Acad Sci U S A. 1997:94:3341-5

93. Grivennikov SI, Greten FR, Karin M. Immunity, inflammation, and cancer. Cell. 2010;140:883-99.

94. Kandathil AJ, Graw F, Quinn J, et al. Use of laser capture microdissection to map hepatitis $C$ virus-positive hepatocytes in human liver. Gastroenterology. 2013;145:1404,1413. e10.

95. Puolakkainen $M$, Vesterinen $E$, Purola $E$, et al. Persistence of chlamydial antibodies after pelvic inflammatory disease. J Clin Microbiol. 1986;23:924-8.

96. Bas S, Muzzin P, Ninet B, et al. Chlamydial serology: comparative diagnostic value of immunoblotting, microimmunofluorescence test, and immunoassays using different recombinant proteins as antigens. J Clin Microbiol. 2001;39:1368-77.

\section{Submit your next manuscript to BioMed Central and we will help you at every step:}

- We accept pre-submission inquiries

- Our selector tool helps you to find the most relevant journal

- We provide round the clock customer support

- Convenient online submission

- Thorough peer review

- Inclusion in PubMed and all major indexing services

- Maximum visibility for your research

Submit your manuscript at www.biomedcentral.com/submit 